\title{
Práticas surpreendentes: uma estratégia de ensino na formação do professor de música*
}

\author{
Astonishing practices: A teaching strategy in music teacher \\ education
}

Kirsten Fink-Jensen

(in memorian)

Tradução:

Ana Ester Correia Madeira*

ana_ecm6@hotmail.com

Teresa Mateiro** teresa.mateiro@udesc.br

\footnotetext{
* Tradução do texto original publicado no Livro Professional Knowledge in Music Teacher Education, editado por Eva Georgii-Hemming, Pamela Burnard e Sven-Erik Holgersen (Farnham, Ashgate, 2013, p.139-155). Aparece aqui sob a permissão de Ole Soegaard, esposo de Kirsten Fink-Jensen (in memoriam).

** Cantora, Professora de Música da Educação Infantil no Educandário Imaculada Conceição (Florianópolis/SC). Mestre em Música pela Universidade do Estado de Santa Catarina (UDESC).

*** Professora Associada da Universidade do Estado de Santa Catarina (UDESC). Atua no Departamento de Música e nos Programas de Pós-Graduação Mestrado em Música (PPGMUS) e Mestrado Profissional em Artes (PROF-ARTES). É doutora em Educação - Educação Musical pela Universidad del País Vasco (Espanha). Realizou pós-doutorado na Lund University (Suécia).
} 


\section{Resumo}

O capítulo de Fink-Jensen centra-se em duas questões fundamentais para o desenvolvimento da prática pedagógica de estudantes de música em formação docente: como a teoria pode contribuir para o desenvolvimento da prática e como a relação entre teoria e prática pode ser abordada durante a formação. Concebendo o professor como um pesquisador propõe a implementação de uma estratégia de ensino que denominou de "práticas surpreendentes", apoiando-se em conceitos antropológicos e fenomenológicos, bem como em teorias do campo da psicologia, da pedagogia e da educação musical. $O$ ponto central é a identificação de uma situação-problema e, para isso, é essencial que o estudante seja capaz de observar de forma aberta e sensível, deixando para trás premissas teóricas já estabelecidas para que possa gerar novas possibilidades para tal situação de ensino.

Palavras-chave: professor pesquisador, técnicas de observação, prática de ensino

\section{Abstract}

The Fink-Jensen's chapter focuses on two key questions (issues) for the development of the pedagogical practice of music students in teacher education: how theory can contribute to the development of practice and how the relationship between theory and practice can be addressed during their education. Conceiving the teacher as a researcher she proposes the implementation of a teaching strategy that he called "astonishing practices", relying on anthropological and phenomenological concepts, as well as on theories of the field of psychology, pedagogy and music education. The central point is the identification of a problem situation and, for this, it is essential that the student is able to observe in an open-sensuous way, leaving behind theoretical premises already established so that it can generate new possibilities for such a teaching situation.

Keywords: teacher as researcher, observation techniques, teaching practice 


\section{Práticas surpreendentes: uma estratégia de ensino na formação do professor de música}

As preocupações de Kirsten Fink-Jensen com a prática pedagógica de seus estudantes são as mesmas de inúmeros professores formadores de muitas outras partes do mundo. Em seu texto, a autora destaca a distância entre os cursos de formação docente e as situações reais do exercício profissional, ou seja, a teoria fundamentada em um ideal de ensino e a prática no cotidiano das salas de aula. Propõe a implementação de uma estratégia de ensino que denominou de "práticas surpreendentes", apoiando-se em conceitos antropológicos e fenomenológicos, bem como em teorias do campo da psicologia, da pedagogia e da educação musical. O ponto central de partida é a identificação de uma situação-problema que se torna evidente durante a prática pedagógica. Para tanto, o estudante em formação docente é convidado a refletir sobre uma ação observada a fim de gerar novas possibilidades para uma determinada realidade.

Tive o privilégio de conhecer a professora dinamarquesa Kirsten Fink-Jensen nos encontros da Rede Nórdica de Pesquisa em Educação Musical (Nordic Network for Research in Music Education), durante os anos em que vivi na Suécia (2007-2010). Entretanto, foi no Encontro realizado na Universidade de Örebro, onde fui professora, que tive um contato mais próximo e me encantei com sua forma de pensar. Foi ela que me indicou para ler e dialogar com a autora de um trabalho de doutorado em andamento sobre o ensino de música para imigrantes na Suécia, durante uma das seções do Encontro. Escolha perfeita, pois eu também era imigrante. Essa desafiadora experiência ficará para sempre em minha memória.

Kirsten Fink-Jensen (1945-2014) foi professora no Departamento de Psicologia e Educação da Escola Superior Dinamarquesa de Formação de Professores e da Faculdade de Educação da Dinamarca (DPU). Atuou no Programa de Mestrado em Educação Musical da DPU, criado em 2006, em colaboração com o Programa de Musicologia da Universidade de Copenhague. Seus estudos centravam-se nas perspectivas fenomenológica e psicológica, assim como na pedagogia da música.

Teresa Mateiro 


\section{INTRODUÇÃO}

"O que significa a experiência no ensino?" "Como formar professores ${ }^{1}$ de música a fim de prepará-los para lidar com situações pedagógicas e, ao mesmo tempo, desenvolver ainda mais sua prática docente? Questões como essas são essenciais a todos os educadores nas universidades, faculdades de educação, escolas de educação básica e escolas de música. Professores recém-formados que atuam no ensino fundamental e médio criticam, com frequência, os currículos de graduação em educação que deveriam tê-los preparado para o magistério. Algumas dessas críticas lidam com a relação entre teoria e prática no programa curricular. "A formação docente é muito teórica", eles dizem, ou "a teoria que aprendemos não tem relação com os problemas que enfrentamos diariamente!" Pode haver muitas explicações para tais questionamentos que não estão relacionadas apenas à estrutura e ao conteúdo dos currículos de graduação em educação, mas também aos métodos específicos de ensino utilizados.

Tenciono discutir as duas questões iniciais (acima) buscando entender como a teoria pode contribuir para o desenvolvimento da prática e como a relação entre teoria e prática pode ser abordada na formação do professor de música. Minha resposta para essas questões se baseia na compreensão do professor como certo tipo de pesquisador. O "professor de música como pesquisador" constitui o tema deste capítulo e é tratado de diferentes formas em outros estudos. Um exemplo bastante conhecido é o livro The Practitioner-Researcher, de Jarvis (1999). Para este trabalho, apoio-me no artigo Music Teachers as Researchers de Brian Roberts (1994). Ele ressalta que a pesquisa em educação musical pode ser caracterizada pelo uso de informação privilegiada do professor de música e que este deve estar envolvido no processo de pesquisa. Defendo que este ponto é um desafio tanto para a pesquisa em educação musical quanto para a formação de professores de música. Defendo, além do mais, que este ponto indica um desafio para o professor formador buscar dois objetivos:

- Ensinar os futuros professores de música acerca das técnicas de observação.

- Ensinar os futuros professores de música como aplicar a teoria na prática.

Proponho a implementação de uma estratégia de ensino, "práticas surpreendentes", a qual eu venho utilizando e desenvolvendo em uma disciplina na universidade por um período de mais de oito anos. Uma "estratégia" de ensino não é o mesmo que um "método" de ensino. Este é um conceito que sugere ao professor as possíveis formas concretas de ensinar que podem ser utilizadas em diferentes situações de ensino. "Estratégias de ensino" são princípios gerais para um procedimento aplicado em uma disciplina e que deve ser seguido pelos alunos. Ao seguir uma estratégia de ensino, os estudantes em formação docente podem usar métodos diferentes, dependendo do problema educacional com o qual eles estão lidando. 
A estratégia de ensino "práticas surpreendentes" foi introduzida como um exercício em uma disciplina do mestrado em educação musical. Os participantes eram professores de música com diferentes qualificações. Alguns eram do programa de musicologia, outros eram professores de música (bacharéis) e outros tinham se formado em conservatórios de música como instrumentistas ou professores de música. Portanto, os alunos do programa almejavam uma carreira profissional em diferentes níveis do sistema educacional.

A condição para a estratégia é entender que a teoria pode e deve contribuir com a prática (KVERNBEKK, 2001) e que o conhecimento teórico é necessário para o desenvolvimento da prática. Portanto, o objeto da estratégia foi desenvolver nos estudantes a compreensão de como a teoria pode auxiliar os professores sobre e durante sua prática.

Exemplos apresentando o modo de dois estudantes utilizarem de forma diferente essa estratégia são incluídos para descrever e discutir como o nível de familiaridade com o campo de trabalho influencia o processo. O estudo empírico de como a estratégia funciona foi baseado em relatórios, entrevistas, diários de campo e questionários de avaliação preenchidos pelos participantes após o término da disciplina.

\section{A IDEIA DAS “PRÁTICAS SURPREENDENTES”}

O ponto de partida da estratégia é um problema, selecionado pelo estudante em formação, que se torna evidente para o estudante que observa em uma situação uma prática na aula de música. O primeiro desafio para o estudante em formação é ser capaz de "ver" um problema. A situação observada pode ser complexa, com muitos fatores diferentes influenciando o que acontece. O problema pode surgir de uma questão musical, mas a relação entre alunos e professor, e entre o professor e o objeto musical também exerce grande influência. Além disso, cada situação de ensino é parte de um contexto institucional condicionado por leis, pela economia, por tradições e, assim por diante. É necessário saber algo sobre todas essas condições para entender o pano de fundo de um problema que aparece na situação observada. O professor tem de refletir pedagógica e psicologicamente sobre como planejar o ensino e responder a diferentes acontecimentos na sala de aula. Porém, a capacidade de responder de forma profissional em momentos específicos exige tanto o conhecimento profissional quanto a capacidade de se posicionar aberta e sensivelmente. Assim, embora a estratégia de ensino "práticas surpreendentes" englobe a introdução de teorias pedagógicas e psicológicas, o ponto central de partida é um problema que se tornou evidente em uma situação prática de ensino. O que o licenciando vê? Ele ou ela fica se perguntando por que algo aconteceu? Para destacar esta parte da estratégia, introduzo o conceito de "surpreendente", fundamentando-me na antropologia. Consequentemente, um dos princípios para a efetivação da estratégia é que o professor em formação deva atuar como observador participante da situação selecionada na aula de música. 


\subsection{Surpresa}

A antropologia cultural entende que a surpresa é um sentimento universal. Os antropólogos encontram diferenças culturais nos sentimentos de admiração, curiosidade, excitação, entusiasmo, simpatia; ao passo que outros podem reagir com horror, indignação, condescendência e até falta de interesse (SHWEDER, 1991). Ficar "surpreso" é um fenômeno - um sentimento - que pode surgir no encontro com algo ou alguém em alguma situação específica. Reside na ruptura com as expectativas desenvolvidas com base em experiências, hábitos ou conhecimentos adquiridos anteriormente. Para experimentar esse sentimento, o professor precisa estar aberto, assumindo a posição de um pesquisador antropólogo, atitude que exige, também, que todas as formas de teoria pessoal ou profissional sejam colocadas de lado por um momento. Um exemplo desses pensamentos pré-definidos podem ser compreensões, teorias pedagógicas ou psicológicas conhecidas ou discursos reais sobre o fenômeno em foco (ZAHAVI, 2001; 2003, p. 21).

Uma questão central neste exercício é como compreender a prática da observação neste contexto. Então, discuto, a seguir, a prática do "ver".

\section{O PROBLEMA DO "VER"}

As observações são baseadas na percepção. Para um observador participante, "ver" não significa apenas usar a visão no sentido biológico, mas em todos os sentidos. É central, na psicologia, a questão de como o conhecimento é gerado. No empirismo, "simplesmente ver" refere-se ao processo sensível que caracteriza a visão: o fato de a luz entrar através da pupila e lançar uma imagem na região fotossensível na parte posterior do olho. O observador complementa essas sensações por meio de associações que resultam da aprendizagem (GLEITMAN; FRIDLUND; REISBERG, 1999, p. 252). Em contraste, os nativistas ${ }^{2}$ argumentam que o observador desempenha um papel ainda mais importante na percepção. A percepção não pode ocorrer sem interpretação e, portanto, eles concluem que os mecanismos utilizados na percepção são inatos. Outras discussões realizadas entre psicólogos resultaram na conclusão de que as realizações da percepção não são puramente aprendidas nem inatas (GLEITMAN; FRIDLUND; REISBERG, 1999, p. 225).

Ver e observar são essenciais não só para os pesquisadores, mas também para os professores. Para refletir e agir sobre um problema identificado no ensino, o educador tem de ser capaz de "ver" o problema. Como veremos mais adiante, a familiaridade com o campo pode ser um problema bem como uma vantagem nessa questão.

Percepção é a palavra-chave na observação participante. Qual seria, então, o papel do conhecimento teórico? Tone Kvernbekk argumenta que "o conhecimento teórico aumenta muito nossa capacidade de ver na prática, principalmente por causa de seu papel vital na percepção cognitiva indireta" (KVERNBEKK, 2000, p. 357).

2 Nota das tradutoras: nativista é aquele que, na antropologia, procura valorizar a cultura do local em reação à imposição de uma cultura externa, em geral dominante. 
Kvernbekk apresenta a diferença entre três ações: "ver", "ver como" e "ver que". Considero essa distinção produtiva em uma discussão sobre como a teoria pode contribuir para a prática com o conhecimento. Segundo Kvernbekk, a noção de "ver" designa um processo simples que não envolve a utilização do conhecimento profissional na formação de uma crença sobre o que se vê. Simplesmente vemos coisas quando olhamos ao redor. Podemos ver um ser vivo voando na floresta, sem saber nada sobre ele. "Ver como", por outro lado, expressa relações entre ver e conhecer. "Ver como" refere-se ao fato de que o observador carrega consigo suas associações, imagens, entendimentos e ações de situações semelhantes anteriores. Por exemplo, um ser vivo voando na floresta pode parecer um floco de neve (ver como), mas podemos saber de experiências anteriores e por meio do conhecimento empírico que, na verdade, é uma espécie de inseto (ver que). As imagens, entendimentos e ações anteriores são sempre parte da perspectiva do observador e afetam sua maneira de ver na situação. Um fenomenólogo argumentaria que a percepção não é simplesmente ver, mas pelo menos "ver como". Não obstante, a fenomenologia almeja "ver" usando a técnica epoché, o processo de tentar colocar a perspectiva pessoal de lado.

A noção "ver que" expressa a relação entre ver e conhecer. "Ver que" permite-nos ver fatos e não apenas objetos, é como uma percepção cognitiva indireta (KVERNBEKK, 2000). Pode haver uma diferença entre o nosso senso comum e o conhecimento que obtivemos nas teorias (por exemplo, as baseadas em pesquisas ou questões filosóficas de nossa educação e formação profissional). Isso é apresentado no modelo da Figura 8.1. O modelo representa a compreensão tanto da noção da teoria quanto da relação entre teoria e prática.

\section{UM MODELO DA RELAÇÃO ENTRE TEORIA E PRÁTICA}

A teoria pode ser colocada em diferentes níveis em relação à prática. Um modelo, exemplo dessa relação, foi feito por Erich Weniger (WENIGER apud IMSEN, 1997).

As teorias são generalizações do conhecimento. Quando um professor ganha experiência em um longo período de ensino, ele desenvolve pressupostos gerais do que é apropriado fazer, junto com opiniões normativas sobre problemas educacionais. Um dos pontos do modelo da Figura 8.1 é que um professor profissional deve ser capaz de usar a teoria em todos os três níveis. Mas, há uma necessidade de distinguir diferentes conceitos de teoria. No primeiro nível, o professor já tem uma perspectiva teórica quando entra em sala de aula (T1 na figura). Algumas dessas teorias não são aparentes, elas são uma parte de uma vivência, um conhecimento implícito de experiências e estudos anteriores. No nível de prática, o professor deve reagir ao que está acontecendo. Em suas ações, ele pode recorrer ao "ver que" do senso comum ou de uma teoria baseada em pesquisa. Algumas posições teóricas podem ocorrer em discussões verbais com colegas antes ou depois da aula (nível T2). Essas teorias podem ser resultado de experiências do que "funciona" nas aulas de música, ou podem decorrer de estudos anteriores e discursos reais sobre o que é importante na educação musical. Vamos chamar o conhecimento dos níveis T1 e T2 de "conhecimento cotidiano". 


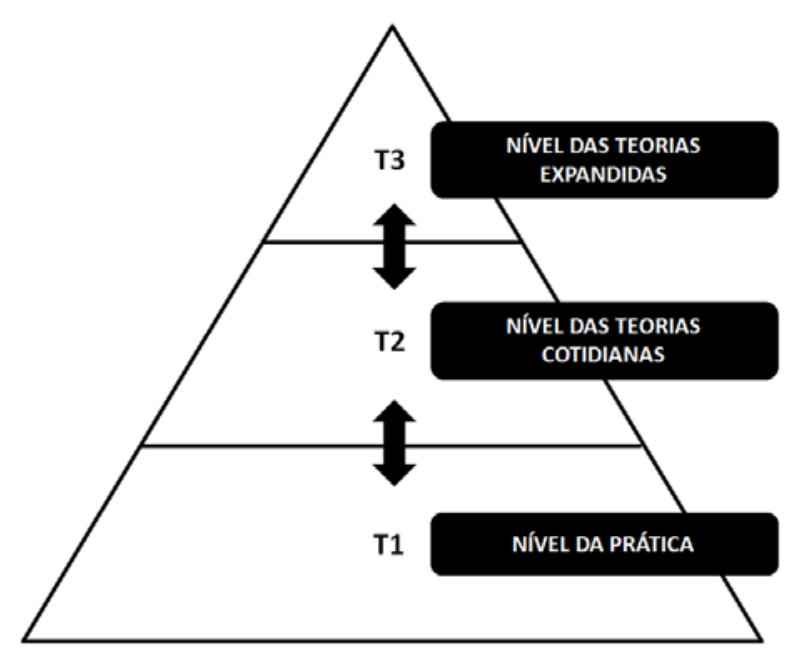

Figura 8.1: Modelo de Erich Weniger de teorias em diferentes níveis

As teorias nos níveis T1 e T2 são todas teorias parcialmente pessoais, as quais são desenvolvidas como resultado de experiências ou uma mistura de experiência com uma compreensão cotidiana de questões que podem envolver a educação musical. Essas teorias são um tanto concretas porque estão ligadas a situações específicas ou a um contexto específico. Esse não é o caso das teorias no terceiro nível (T3), pois elas são abstratas, desenvolvidas como afirmações gerais sobre questões psicológicas, filosóficas ou pedagógicas. Elas são baseadas em uma argumentação cuidadosa e/ou em resultados empiricamente fundamentados. Essas teorias são instrumentos de reflexão sobre questões pedagógicas que emergem nas situações de ensino; teorias que tornam possível ao professor desenvolver sua prática pedagógica. Com o passar do tempo, novas teorias podem ser incorporadas e tornar-se parte do conhecimento cotidiano do professor. A capacidade de refletir nesse nível é o objetivo do trabalho quando se trata de aplicar a estratégia de "práticas surpreendentes".

"Teoria" não é um conceito preciso. Existem muitos modelos teóricos diferentes na educação. Kvernbekk descreve duas concepções gerais da teoria: uma é a sintática (positivista) e a outra é a semântica (KVERNBEKK, 2005). A concepção sintática é baseada em uma hipótese que é confirmada cientificamente; a semântica toma como ponto de partida um problema ou fenômeno ocorrido em um contexto educacional. Seguindo a posição semântica, as teorias são construídas dos fenômenos observados.

A estratégia das práticas surpreendentes é baseada no modelo teórico semântico. A formação de uma nova teoria acontece em dois passos ou, mais especificamente, dois processos de abstração. O primeiro é uma descrição escrita do fenômeno em foco, enfatizando os aspectos mais interessantes em uma reflexão de senso comum. $O$ segundo processo da abstração é baseado na análise de uma perspectiva teórica relevante (T3). A seguir um exemplo de como isso pode acontecer. 
Um grupo de alunos do primeiro ano irá tocar em conjunto uma peça rítmica. Eles estão tocando instrumentos diferentes. Uma menina, Anne, está tocando o instrumento conga. $O$ professor mostra às crianças como tocar e elas tentam seguir o professor. Anne não toca na primeira vez e continua olhando para o professor. Em seguida, ela olha para as mãos dos outros alunos. Finalmente, ela olha para suas próprias mãos e começa a tocar. Todos conseguem tocar a música, com exceção de Anne. As outras crianças sentem a batida da música e tocam sincronicamente enquanto Anne não consegue seguir o movimento rítmico.

Do ponto de vista do senso comum, o problema pedagógico nesse caso está relacionado à participação de Anne na atividade musical. Questões gerais podem estar relacionadas com as competências rítmicas das crianças aos sete anos de idade e como o professor pode reagir quando a criança tem dificuldade em sentir o ritmo de uma peça musical. Uma possibilidade é estudar teorias das competências rítmicas das crianças encontradas na área da psicologia sobre o desenvolvimento musical das crianças (HARGREAVES, 1986). Os pensamentos de um professor sobre como se relacionar com o problema podem ser elucidados em diferentes teorias acerca da didática e da formação 3 (NIELSEN, 1998).

Em outras palavras, o processo analítico consiste em dois passos: primeiro, é necessário reduzir o fenômeno a uma questão central. O professor precisa de ferramentas analíticas para fazer essa abstração. Em primeiro lugar, o professor deve perguntar: "O que significa o fato de Anne não sentir a pulsação da música?". Várias explicações diferentes são possíveis: talvez a criança estivesse tendo uma manhã não muito boa e estivesse com dificuldades para se concentrar (uma questão de humor). Ou ela pode ter problemas no movimento das suas mãos (uma questão de desenvolvimento de habilidades motoras). Ou ela não percebe a estrutura rítmica da música (uma questão de desenvolver a percepção rítmica).

Existem outras possíveis explicações. Quando o professor seleciona uma delas, ele faz uma abstração de um conjunto de fatos.

Segundo, o processo analítico deve continuar a partir de outras perspectivas relacionando-as com a principal abstração. Esse processo é um movimento para o próximo passo, o qual envolve a construção de uma teoria com base em argumentações documentadas e, em determinadas formas de pesquisa, regras mais imperativas. A parte final desse processo é baseada na contribuição das teorias no nível T3.

Estes dois processos fazem parte da fase analítica no exercício das práticas surpreendentes.

O resultado de minhas reflexões sobre a relação entre teoria e prática e como implementá-las na formação de professores de música é o desenvolvimento do modelo descrito abaixo. 


\section{O MODELO DAS PRÁTICAS SURPREENDENTES}

A parte prática dessa estratégia de ensino consiste em cinco fases, as quais são comuns para vários tipos de pesquisa que usam o método qualitativo (HAAVIND, 2000; RØNHOLT; HOLGERSEN; FINK-JENSEN; NIELSEN, 2003). O modelo é um exemplo de como usar a observação participante na educação, tendo a pesquisa como inspiração. As descrições das cinco fases estão a seguir.

\subsection{A fase da preparação}

O contato e o conhecimento prévio são as palavras-chave nesta fase. O licenciando faz contato com um professor ou escolhe uma situação de sua própria prática. Em ambos os casos, ele leva em consideração seu conhecimento prévio da prática selecionada e escreve-a antes que a observação ocorra. Nesta fase, a gravação em vídeo não é relevante.

\subsection{A fase da observação}

O estudante está presente com uma câmara de vídeo na prática selecionada. Ele pode participar de duas maneiras diferentes: como um observador externo ou como um professor. Como um observador externo, ele grava em vídeo ou faz anotações sobre observações importantes durante a situação; como professor ele faz anotações após a situação. As anotações podem ter como suporte as descrições da estrutura física da sala, das instalações e dos participantes. É relevante também colocar algumas perguntas ao professor antes da observação, como as questões a seguir:

- Qual é o conteúdo? Quais são as atividades musicais? Qual é o tipo de música?

- Qual é o objetivo do ensino?

- Por que os alunos irão aprender esse assunto?

- Como eles devem ser ensinados? Que métodos podem ser úteis?

- Quais os materiais devem ser usados?

- Por que este é o momento ideal para ensinar este assunto, dadas as qualificações dos alunos?

- Quais são as características da instituição em que o ensino acontece?

Durante ou depois da observação, o estudante toma nota dos sentimentos, sensações e experiências surpreendentes. Tomar notas é apenas uma das técnicas usadas na observação participante. Entrevistas com os participantes são relevantes complementos para as observações. A gravação em vídeo dessa fase é essencial, o que se torna evidente nos exemplos abaixo.

\subsection{A fase da coleta de dados}

O estudante descreve com base em observações, entrevistas e anotações, focando no que o surpreendeu com relação aos seus conhecimentos prévios. As descrições 
são um resultado da primeira análise no senso comum. Na primeira descrição, o estudante tem de ser muito aberto e tornar o comportamento dos participantes claro para o leitor. A gravação de vídeo lhe oferece a possibilidade de comparar as observações com as anotações do diário de campo. Podem ser feitas gravações adicionais e o exercício pode ser completado usando a técnica de "estimulação de recordação", que inclui uma apresentação das gravações de vídeo aos participantes selecionados. Os comentários desses participantes podem, então, fornecer informações importantes no processo de análise. Mais tarde, o estudante tem de mostrar sua gravação de vídeo para outros colegas para descobrir como eles entendem a situação. O estudante deve fazê-lo sem revelar sua própria compreensão da situação.

\subsection{A fase da análise}

Nesta fase, o aluno pode recorrer a uma variedade de informações e perspectivas teóricas para refletir sobre os fenômenos observados. Neste processo, as gravações de vídeo são um material importante para um estudo mais aprofundado e analítico dos detalhes da situação. Depois de estudar as gravações de vídeo, o estudante escolhe o fenômeno central e decide quais teorias são capazes de lançar luz sobre isso. A decisão pode ser discutida com outras pessoas - outros estudantes, ou os próprios participantes observados. Esta fase é a base para um produto (um texto) a ser usado na próxima fase.

\subsection{A fase da apresentação}

Esta fase diz respeito ao relatório e à apresentação oral. O estudante apresenta seu projeto de forma escrita e verbal como um tópico para discussão. A apresentação final ocorre quando o estudante faz uma prova oral e escrita. Ele faz um relatório de 25 páginas que é o ponto de partida para uma discussão entre o estudante e o professor.

Essas cinco fases não são cronológicas. Os três primeiros passos devem ser realizados um após o outro. Mas, na fase analítica o aluno se movimenta entre o material dos dados e as diferentes perspectivas teóricas, como em uma espiral hermenêutica (FINK-JENSEN, 2007).

O ponto de partida não é um estudo de teoria ou pesquisa anterior, seguido por uma pergunta de pesquisa para orientar o projeto. Desta forma, esta estratégia difere de outras estratégias corriqueiras do professor. Embora o objetivo da estratégia seja obter uma visão sobre como a teoria pode contribuir para o desenvolvimento da prática, o ponto de partida é empírico. O procedimento pode lembrar a "teoria fundamentada", mas a abordagem é diferente. O primeiro passo do processo analítico é baseado em um método fenomenológico. A diferença é que, desde o início, a perspectiva em primeira pessoa sempre tem de aparecer. Este posicionamento se baseia na constatação de que o professor ou pesquisador sempre tem experiências, expectativas, sentimentos e interesses prévios que influenciam sua maneira de ver e a teoria da prática que está em jogo em uma determinada situação.

No próximo tópico, apresentarei o modo como a estratégia foi implementada na 
disciplina. A implementação revelou alguns problemas. A capacidade dos estudantes de ter uma atitude aberta como um observador participante parecia depender do seu grau de experiência como professores de música. Vou apresentar este problema em dois casos com dois alunos diferentes.

\section{A IMPLEMENTAÇÃO DAS PRÁTICAS SURPREENDENTES}

A prática pedagógica dos estudantes de música em formação docente foi marcada pelo fato de eles terem de trabalhar com um caso baseado em estudos empíricos. As observações foram realizadas em escolas do ensino fundamental ou médio, ou na universidade, no conservatório ou em uma escola livre de música.

O estudante em formação trabalhava em conjunto com o professor de música que concordou em participar do projeto do estudante. Alternativamente, o próprio estudante poderia observar a própria prática, o que, por sua vez, implicou outras questões e proporcionou um desafio particular.

Antes de iniciar o projeto, cada estudante foi orientado a escrever suas próprias expectativas relacionadas ao local e aos participantes. Para entender a sua própria perspectiva pessoal, ele tinha de escrever suas próprias condições e conhecimentos prévios. Que tipo de educação musical ele vivenciou na escola, no tempo livre ou em outra circunstância? Ele tinha consciência das suas preferências pedagógicas ou musicais? Poderia haver uma tendência para esquecer essas expectativas e preferências depois de ter feito as observações.

Com a intenção de preparar os alunos para o trabalho empírico, foram introduzidos e discutidos métodos de pesquisa. A disciplina incluía, em particular, uma introdução a respeito de como criar um estudo de caso; o método e as questões relacionadas à "observação participante"; o uso de diferentes técnicas, como gravações em vídeo e entrevista de estimulação de recordação, e uma introdução sobre a análise do material empírico. Para a análise, o estudante tinha de encontrar teorias relevantes. Para esse propósito, foram introduzidos diferentes tipos de teorias básicas psicológicas e educacionais. Ao trabalhar com seus projetos individuais, os estudantes muitas vezes tiveram de complementá-los com outras teorias para esclarecer o fenômeno escolhido.

Ao colocar em prática a estratégia das práticas surpreendentes, ocorreram vários problemas que são comuns a outros métodos de pesquisa. No entanto, a seguir, enfatizarei apenas um problema específico encontrado pelos estudantes de música em formação.

$\mathrm{Na}$ introdução, referi-me ao que Brian Roberts disse sobre a informação privilegiada do professor de música ser uma vantagem para a pesquisa em educação musical. O estudante de música em formação também tem um tipo de familiaridade com as situações que ele observa. Familiaridade é algo que tem a ver com as perspectivas pessoais. Em uma pesquisa baseada em princípios fenomenológicos, a perspectiva pessoal sempre deve ser considerada. A familiaridade, portanto, é um ponto forte, mas também é um problema. Nos dois exemplos a seguir, mostro como a familiaridade foi um problema para dois diferentes estudantes de música em formação que estavam trabalhando com as "práticas surpreendentes". 


\subsection{Familiaridade: a questão chave para o uso da estratégia}

O uso das 'práticas surpreendentes' era algo novo para os estudantes, e foi difícil, para eles, deixar de lado abordagens teóricas para o projeto desde o início. No entanto, isso era necessário, porque a surpresa depende da capacidade do estudante de estar presente de forma aberta e sensível, deixando para trás as premissas teóricas tanto pessoais quanto estabelecidas.

Isso nos leva ao fato de que os estudantes tiveram de desenvolver técnicas para refletir sobre sua perspectiva pessoal. Esta necessidade tornou-se especialmente evidente em minha pesquisa quando o professor era muito experiente. Um professor experiente tem a vantagem de ter muitas ideias sobre o que fazer e conhecimento sobre o que funciona. Ele desenvolveu uma posição normativa, de maneira que sua perspectiva pessoal dominou a ponto de impedi-lo de observar de forma aberta e sensível. Ele desenvolveu certo tipo de cegueira. A "surpresa de Dinah" (a seguir) é um exemplo de como isso ocorreu em minha pesquisa na universidade.

Dinah era um dos professores mais experientes no grupo de estudantes em formação. Contudo, todos tinham algum nível de familiaridade com o campo de observação. Essa familiaridade se originou da participação deles como aprendizes ou professores nas aulas de música em escolas, escolas livres de música, universidade ou outros contextos musicais. Embora a familiaridade possa capacitar o observador a compreender várias atividades práticas e acadêmicas, ela pode prejudicá-lo ao observar problemas em situações educacionais. A familiaridade faz parte do conhecimento cotidiano que pode influenciar uma impressão mais sensível na situação observada. Portanto, eu tive de considerar a questão de como a familiaridade de um estudante com o campo observado poderia influenciar sua habilidade para observar de forma sensível e aberta. O que a estratégia das práticas surpreendentes oferece para resolver este problema para estudantes com níveis muito diferentes de experiência no ensino? Para ilustrar e discutir este problema, descrevo a seguir a "surpresa" que se tornou evidente em suas descrições das observações de aulas de música em uma escola pública e em outra do ensino médio. Para ilustrar e discutir este problema, descrevo a seguir a surpresa de dois estudantes que se tornou evidente nas descrições de suas observações de aulas de música em uma escola de ensino médio.

\subsection{A surpresa de Michael}

Michael é um estudante de vinte anos com uma experiência de ensino limitada. Estudou musicologia na Universidade de Copenhagen e nunca tinha cursado uma disciplina de didática da música. Michael e outros três estudantes entraram em contato com um professor de uma escola de ensino médio e marcaram para realizar a gravação em vídeo de uma aula de música. No dia combinado, o professor não estava presente por motivos de saúde. Assim, Michael concordou em ministrar a aula enquanto os outros estudantes participaram sentados na sala com uma câmera de vídeo. Michael não conhecia os alunos da turma e, por causa de suas experiências anteriores no ensino médio, ele não 
nutriu grandes expectativas no que concerne a eles.

\begin{abstract}
A aula é sobre cantar em um coral. Primeiramente, Michael pediu que os alunos se organizassem em um semicírculo. Depois, ele pediu às sopranos para ficarem do lado direito e às contraltos do lado esquerdo. De imediato uma menina perguntou: "O que eu sou?" Michael respondeu: "Aquelas que possuem uma voz aguda, vão para direita, e aquelas que possuem uma voz grave, à esquerda". As meninas discutiram o assunto entre si e uma delas perguntou: "Sopranos são as vozes graves, não são?". Duas meninas logo foram para a direita. Uma menina, então, solicita: "Você poderia, por favor, mostrar quais notas você quer que cantemos?". Primeiro, Michael tocou uma nota aguda ao piano. Em seguida, ele a demonstrou cantando em falsete. Todas as meninas riram e depois todas as meninas do grupo das sopranos se deslocaram para o grupo das contraltos.
\end{abstract}

Apesar de não ter grandes expectativas, Michael ficou surpreso com a falta de conhecimento dos alunos sobre os termos musicais. Michael usou um vocabulário acadêmico que ele entendia como uma linguagem comum, mas parecia não ser o caso. Ele levou muito tempo para entender isso.

A surpresa de Michael se encontra nas competências acadêmicas dos alunos. Ele não as conhecia e isso gerou problemas de comunicação. Sua abordagem prática de educação musical é baseada em "tentativa e erro" em função de sua falta de experiência. A vantagem da "tentativa e erro" como estratégia de ensino é a sua flexibilidade: o professor sabe que ela pode não funcionar. Ele está pronto para experimentar um novo método. Na comunicação com as meninas isso se tornou evidente. O desafio é explicar o significado das palavras soprano e contralto. Ele pode tocar uma nota, cantá-la ou usar a linguagem, falando sobre vozes agudas e graves. Seu conhecimento sobre esses diferentes métodos se baseia em sua educação musical e em sua experiência prévia. Ele tem muita familiaridade com o vocabulário musical e é também capaz de usar esse conhecimento. Ele tem competência profissional na matéria de música, mas não está preparado para a prática do ensino.

No processo de ensino, Michael teve problemas pedagógicos devido à sua inexperiência, mas, por outro lado, sua "observação" não foi influenciada por concepções pedagógicas normativas desenvolvidas ao longo dos anos por meio da prática docente. Ele analisou o problema de forma aberta, discutindo-o sob a perspectiva do "incômodo didático" e a questão das competências do professor em relação à capacidade de atuar na situação (RØNHOLT, 2003). O "incômodo didático" é um fenômeno de nível fenomenológico (realidade observada) que se manifesta através das expressões e ações corporais e verbais, sendo de crucial importância para os processos de ensino e aprendizagem. Um incômodo didático oferece a possibilidade de uma "situação pedagógica" (uma oportunidade imprevista para a ação pedagógica).

\title{
6.3 A surpresa de Dinah
}

A estudante Dinah tem mais de quarenta anos e tem grande experiência no ensino de música em diferentes escolas e níveis. Atualmente, ela está ensinando música para 
professores do centro de recreação e está cursando didática da música na Escola Dinamarquesa de Educação. Assim, ela tem os pré-requisitos necessários para poder refletir sobre as situações pedagógicas no Nível T3.

Dinah observou uma aula com crianças do segundo ano de uma escola pública. A atividade musical era um jogo de canto com movimentos. Dinah descreveu a situação da seguinte forma:

As crianças estão em pé em um círculo. Eles vão ensaiar uma nova música. $O$ texto tem muitas palavras e nem o texto nem a melodia são fáceis de lembrar. $O$ professor apresenta a música às crianças, falando sobre uma "nova dança" e, ao mesmo tempo, mostrando a coreografia. As crianças estão conscientes dos movimentos. Imitando os movimentos do professor, elas se "esquecem" de cantar.

Depois da observação, Dinah estudou a gravação em vídeo e escreveu sobre seus sentimentos em um nível de senso comum (em itálico estão as suas reflexões didáticas, sem destaque são suas próprias observações):

No vídeo, vi que as crianças estavam muito engajadas na atividade de canto.
Mas, eu também vi que foi muito difícil para elas aprender uma nova melodia, um
novo texto e a coreografia ao mesmo tempo. Acredito que teria sido uma ideia
melhor ensinar separadamente as três partes da atividade. Talvez as crianças ti-
vessem tido mais condições para cantar a música. Eu notei também que a mú-
sica não tinha acompanhamento e estava numa tonalidade baixa. Acredito que
um acompanhamento poderia ajudar as crianças a cantar no tom. Eu também
acredito que seria mais fácil para as crianças cantarem em uma tonalidade mais
aguda. Percebi que as crianças estavam preocupadas, principalmente, com a co-
reografia. Pergunto-me se é possível que as crianças dessa idade façam tantas
coisas ao mesmo tempo e também tenham uma experiência estética. Mais tarde,
eu vi que a parte cantada da atividade estava dando suporte à coletividade. Essas
observações me levaram a querer escrever sobre a atividade de canto porque
acredito que, para essa idade, é uma disciplina fundamental no ensino de música.

Em suas reflexões, ela não pôde deixar de usar o seu próprio conhecimento sobre esse tipo de atividade. O seu especial interesse no canto é muito evidente. A sua "surpresa" é expressa na frase: Pergunto-me se é possível que as crianças dessa idade façam tantas coisas ao mesmo tempo e também tenham uma experiência estética. Além disso, Dinah ficou surpresa pelo fato de as vozes das crianças não serem trabalhadas pedagogicamente e que não fosse dada atenção para cantar em uma tonalidade apropriada e natural para a extensão da voz infantil. Na perspectiva normativa de Dinah isso foi um problema. Uma conclusão é que a sua surpresa estava principalmente naquilo que o professor não fez! Por esta razão, ela perguntou ao professor sobre seus objetivos educacionais nessa atividade. O professor respondeu que o andamento era o foco e o objetivo era criar uma sensação de comunidade musical, fazendo uma orquestra de vozes sem instrumentos. Os objetivos da atividade de cantar foram:

- Que as crianças se divertissem fazendo parte da atividade. 
- Que as crianças adquirissem, indiretamente, novos conhecimentos sobre música

- Que movimento e canto pudessem acontecer juntos

- Que as crianças adquirissem conhecimento sobre diferentes formas musicais de expressão, neste caso, a combinação de som e movimento.

A teoria do cotidiano do professor era que a combinação de som e movimento poderia ser transferida para situações do dia-a-dia. Ele presumiu que a capacidade de combinar e coordenar diferentes expressões são essenciais para o desenvolvimento do cérebro e da educação em geral. O professor pensa que muitos adultos hoje são incapazes de coordenar canto e movimento, e que a integração dos movimentos em uma atividade de canto é mais fácil para as crianças. De um modo geral, é importante que as crianças se movam porque o movimento fortalece a capacidade para aprender e, ao mesmo tempo, faz com que as crianças fiquem mais relaxadas.

Assim, esse conhecimento cotidiano deu ao professor uma boa razão para realizar a atividade. A surpresa de Dinah apontou para um dilema entre as intenções do professor e a capacidade das crianças de fazer várias coisas ao mesmo tempo. Dinah, com seu particular interesse no cantar, notou aquilo que não funcionava, mas ela só foi capaz de observar uma pequena parte do processo. Talvez o conhecimento de Dinah sobre a voz infantil fosse maior que o do professor. $O$ fato é que a surpresa de Dinah foi uma espécie de incômodo didático ligado a uma pergunta: "Por que o professor não vê a possibilidade de ensinar a cantar?" (isso era importante para Dinah, mas não para o professor). Dinah admitiu que, nessa situação, ela se coloca na posição do professor e pensa em como ela mesma agiria.

Isso destaca a questão das perspectivas teóricas que ela trouxe para a sala de aula. A maneira como Dinah lidou com o exercício se caracterizou por sua posição normativa. As teorias que ela desenvolveu em sua própria prática dominaram suas reflexões e, para ela, foi difícil olhar sua própria posição a partir de uma meta-perspectiva. A vantagem desse posicionamento é o conhecimento dela sobre "o que é possível" em uma situação como essa e o seu conhecimento sobre a voz. O perigo do seu posicionamento é que, sem uma atitude autorreflexiva, ela pode escolher, na análise, teorias que enfatizam suas próprias preferências ao invés de tentar desafiar suas próprias preconcepções. Em vez de abordar a questão da importância do canto, ela deveria estar aberta na primeira abstração analítica de sua observação e perguntar sobre os termos da atividade: o professor atingiu o objetivo dessa atividade? Se não, quais problemas ocorreram? Também é possível lidar com um problema relativo ao conhecimento musical do professor participante por meio de uma questão mais geral: quais as competências musicais necessárias para o professor implementar esse tipo de atividade musical? Esta é uma questão muito mais aberta à discussão detalhada do que o desejo de Dinah de escrever sobre a importância da atividade de canto. Existe o perigo de que escrever sobre a importância do canto não represente um desafio, mas apenas confirme o seu posicionamento. 


\subsection{Familiaridade: problema ou vantagem?}

Esses exemplos parecem indicar que é mais fácil para professores inexperientes ter uma atitude aberta. Michael ainda não desenvolveu uma posição normativa; cada reação dos alunos é um desafio para ele. Por causa de suas perspectivas teóricas, é fácil para ele analisar o fenômeno, embora ele ainda precise de algum treinamento para poder atuar a partir do resultado de suas reflexões na prática. No caso de Michael, ele vivencia diretamente situações-problema. Isto é também algo que tem a ver com a música como disciplina. Em muitas atividades musicais há uma exigência para a performance e o aluno torna-se muito visível para o professor que, então, seja capaz de observar o resultado das suas iniciativas.

As práticas surpreendentes não substituem a formação prática pedagógica de que Michael precisa. Mas o exercício proporciona a oportunidade para que ele possa treinar suas habilidades analíticas em um episódio concreto advindo da prática. Para fazer isso, ele precisa de conhecimento teórico pedagógico ou psicológico.

Dinah tem muita experiência no ensino de música. Ela está familiarizada com as atividades que observa e sabe o que é melhor! Isso cria sérios problemas na fase analítica. O principal problema é como ela pode aprender a "ver" suas próprias considerações normativas (FIELD; LATTA, 2001). A estratégia das práticas surpreendentes baseia-se na necessidade de refletir sobre o próprio posicionamento. Isso acontece no confronto com as perspectivas de outros estudantes ao assistir à gravação de vídeo. Ao repetir o estudo da gravação de vídeo, ela verá algo que não era visível durante a primeira observação. Essas etapas são maneiras de criar uma distância de si mesmo, vendo-se como parte da situação. De modo ideal, isso pode resultar em uma importante autoconsciência que pode melhorar sua visão ao criar novas questões ao invés de usar explicações tradicionais. Uma questão central é: é possível entender esse fenômeno de outra maneira? Dinah imediatamente "vê que". Porém, sua base para "ver que" são experiências anteriores e as preferências que ela desenvolveu em relação ao canto no ensino de música. Não traz novas ideias para ela. Isso teria sido possível se ela estivesse aberta às intenções do professor. No entanto, seu conhecimento profissional de canto é forte e permite que ela critique o conhecimento profissional do professor.

A conclusão é que a gravação de vídeo é de grande importância na estratégia por exemplo, no posicionamento de Michael como professor e pesquisador. Ao olhar para as gravações de vídeo, foi possível que ele refletisse sobre sua própria participação e discutisse a situação com três estudantes que o acompanhavam. Meu estudo sobre a implementação da estratégia da prática surpreendente, na minha experiência de ensino, tem mostrado que o processo de anotar as preconcepções em combinação com a observação de vídeo é uma maneira importante para o estudante desenvolver sua autoconsciência de forma mais aprofundada. Esse pré-conhecimento dá ao estudante um acesso parcial ao seu conhecimento tácito, enfatizando suas expectativas. Estas expectativas podem ser provocadas na situação, ampliando suas considerações pedagógicas normativas. Esse processo é reforçado ao analisar as gravações de vídeo e ao apresentá-las para outras pessoas - por exemplo, em uma entrevista usando a técnica 
de estimulação de recordação (LYLE, 2003) em um diálogo com o professor observado. Nesse processo, sua teoria cotidiana será desafiada por outras teorias em todos os níveis. Alguns alunos precisaram de muito apoio de minha parte nesse processo e muitos anos de familiaridade com o campo não pareceu ser, necessariamente, uma vantagem. As gravações de vídeo, em sua maioria, forneceram uma grande quantidade de informações a todos os estudantes e, assistindo-as várias vezes, eles experimentaram um avanço na própria compreensão.

\section{CONCLUSÃO}

No início deste artigo perguntei: "O que significa a experiência no ensino?" "Como formar professores de música a fim de prepará-los para lidar com situações pedagógicas e, ao mesmo tempo, desenvolver ainda mais sua prática docente?". Implementar a estratégia de ensino "práticas surpreendentes" oferece uma oportunidade para que os estudantes possam observar problemas na educação musical e lidar com eles. Seguindo esta estratégia, é necessário que os estudantes tenham experiência em primeira mão de uma prática de ensino de música. Mas, estar presente na situação não é suficiente. Os estudantes precisam ter conhecimento sobre métodos de pesquisa - em particular de observação participante - e, na análise, algumas teorias pedagógicas e psicológicas relevantes.

O argumento de Brian Roberts sobre a importância da informação privilegiada do professor de música foi discutido nos exemplos de Dinah e Michael. A familiaridade com a situação é ao mesmo tempo uma vantagem e um desafio. As atitudes normativas estão intimamente ligadas à familiaridade. No decorrer do tempo, teorias e experiências da prática se misturam em um tipo de personificação e podem resultar em ideias normativas. O desafio é, então, continuar a ser capaz de adotar uma atitude aberta.

Experiência no ensino não é apenas experiência prática, mas também experiência de usar a teoria na prática. Essas experiências devem se basear em um alto grau de abertura para novos entendimentos de como lidar com problemas bem conhecidos.

\section{Perguntas para reflexão}

1. Como vocês entendem o conceito de surpresa neste capítulo e por que ele é importante?

2. Como o professor pode se preparar para estar presente de maneira aberta e sensível nas situações de ensino?

3. Como o conhecimento teórico pode contribuir para o desenvolvimento da prática?

\section{REFERÊNCIAS}

FIELD, James C.; LATTA, Margaret A. Macintyre. What constitutes becoming experienced in teaching and learning? Faculty Publications: department of teaching, learning and teacher education, 2001. Disponível em: <http://digitalcommons.unl.edu/teachle- 
arnfacpub/5>. Acesso em: 17 de Setembro de 2012.

FINK-JENSEN, Kirsten. Attunement and bodily dialogues in music education. Philosophy of Music Education Review, n. 15, v.1, p. 53-68, 2007.

GLEITMAN, Henry; FRIDLUND, Alan J.; REISBERG, Daniel. Psychology. New York: W. W. Norton, 1999.

HAAVIND, Hanne (Ed.). Kjønn Og Fortolkende Metode: metodiske muligheter i kvalitativ forskning. Oslo: Gyldendal Akademisk, 2000.

HARGREAVES, David J. The Developmental Psychology of Music. Cambrige: Cambrige University Press, 1986.

IMSEN, Gunn. Lærerens Verden: innføring i generell didaktik. Oslo: Tano Aschehoung, 1997.

JARVIS, Peter. The Practitioner-Researcher: developing theory from practice. San Francisco, CA: Jossey-Bass, 1999.

KVERNBEKK, Tone. Pedagogisk Teoridannelse: insider, teoriformer of praksis. Bergen: Fagbokforlaget, 2005.

KVERNBEKK, Tone. Seeing In Practice: a conceptual analysis. Scandinavian Journal of Educational Research, n. 44, v. 4, 358-370, 2000.

KVERNBEKK, Tone. Teorityper og bruk av teori. In: NIELSSEN, Frede V.; JØRGENSEN, Harald (Eds.). Nordisk Musikkpedagogisk Forskning årbok 5. Oslo: NMH-publikasjoner, Norges Musikkhøgskole, p. 25-42, 2001.

LYLE, John. Stimulated Recall: a report in its use in naturalistic research, British Educational Research Journal, n. 29, v. 6, p. 861-878, 2003.

NIELSEN, Frede V. Almen Musikdidaktik. Copenhagen: Akademisk Forlag, 1998.

ROBERTS, Brian. Music teachers as researchers, International Journal of Music Education, n. 23, v. 1, p. 24-33, 1994.

RØNHOLT, Helle. Didaktiske irritationer. In: RØNHOLT, Helle; HOLGERSEN, Sven-Erik; FINK-JENSEN, Kirsten; NIELSEN, Anne Maj (Eds.). Video i Pædagogisk Forskning: krop og udtryk i bevægelse. Copenhagen: Forlaget Hovedland, p. 106-153, 2003.

RØNHOLT, Helle; HOLGERSEN, Sven-Erik; FINK-JENSEN, Kirsten; NIELSEN, Anne Maj. Video i pædagogisk forskning: krop og udtryk i bevægelse. Copenhagen: Forlaget Ho- 
vedland, 2003.

SHWEDER, R. A. Thinking Through Cultures: expeditions in cultural psychology. Cambrige, MA: Harvard University Press, 1991.

ZAHAVI, Dan. Beyong Empathy: phenomenological approaches to intersubjectivity, Journal of Consciousness Studies, n. 8, v. 5-7, p. 151-167, 2001.

ZAHAVI, Dan. Fænomenologi. Copenhagen: Roskilde Universitetsforlag, 2003. 